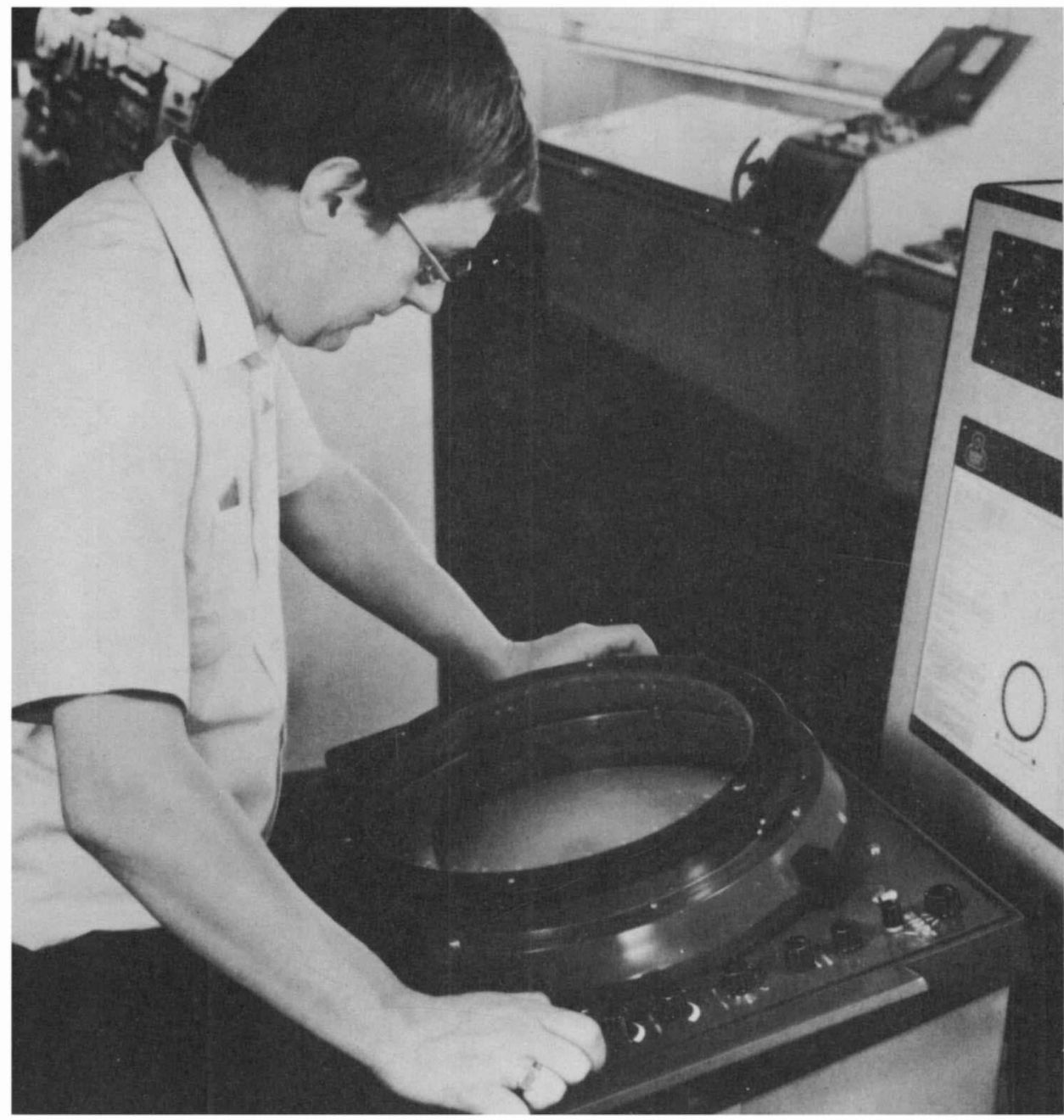

\title{
$3 \mathrm{~cm}$ and now $10 \mathrm{~cm}$ Radiolocator radars A sea-proven combination to be considered
}

Radiolocator is the longest running name in marine radar - and surely one of the most trusted.

Radiolocator now means $3 \mathrm{~cm}$ or $10 \mathrm{~cm}$

radars, 12-inch or 16-inch displays and a

thoroughly reliable, well-proven design that

ensures maximum life expectancy from expensive, consumable components.
All the convent ional radar facilities are standard on both $3 \mathrm{~cm}$ and $10 \mathrm{~cm}$ Radiolocators They can be enhanced with options such as compass stabilisation, true motion and radar interference suppression.

Radiolocator from Marconi. $3 \mathrm{~cm}$ or $10 \mathrm{~cm}$. You can depend on it.

\section{Marconi Marine radar}

The Marconi International Marine Co. Ltd.

Chelmsford Essex England.

Tel: (0245) 61701 Telex: 99228

A GEC-Marconi Electronics Company 


\section{THE \\ INTERNATIONAL HYDROGRAPHIC REVIEW}

Half-yearly, 160 pages (approx.) $18 \times 27 \mathrm{~cm}$. Price 75 French francs* Yearly subscription 140 French francs*

Among the papers of interest in the January 1982 issue are:

- NAVSTAR Global Positioning System

(J. H. NORTON)

- U.K. charting practice in the implementation of IALA Maritime Buoyage System "A"

$$
\text { (P. WAinWRight) }
$$

- Loran-C coordinate converters - Plague or panacea

(D. H. Gray \& T. Mortimer)

PUBLISHED BY THE

INTERNATIONAL HYDROGRAPHIC BUREAU

7, av. President J. F. Kennedy,

B.P. 345 - MC 98000 MONACO

The Bureau also publishes monthly

THE INTERNATIONAL HYDROGRAPHIC BULLETIN

A bilingual journal-English and French-giving news of hydrographic activities worldwide. Lists in detail charts published by Member States of the International Hydrographic Organization, and contains a selective bibliography of recent works in the fields of hydrography, descriptive oceanography, navigation, cartography, etc.

Approx. 30 pages, $21 \times 30 \mathrm{~cm}, 9.50$ French francs per copy* Yearly subscription: 95 French francs*

\section{* Postage extra in all cases}




\section{The MX3102. Easier than ever to own.}

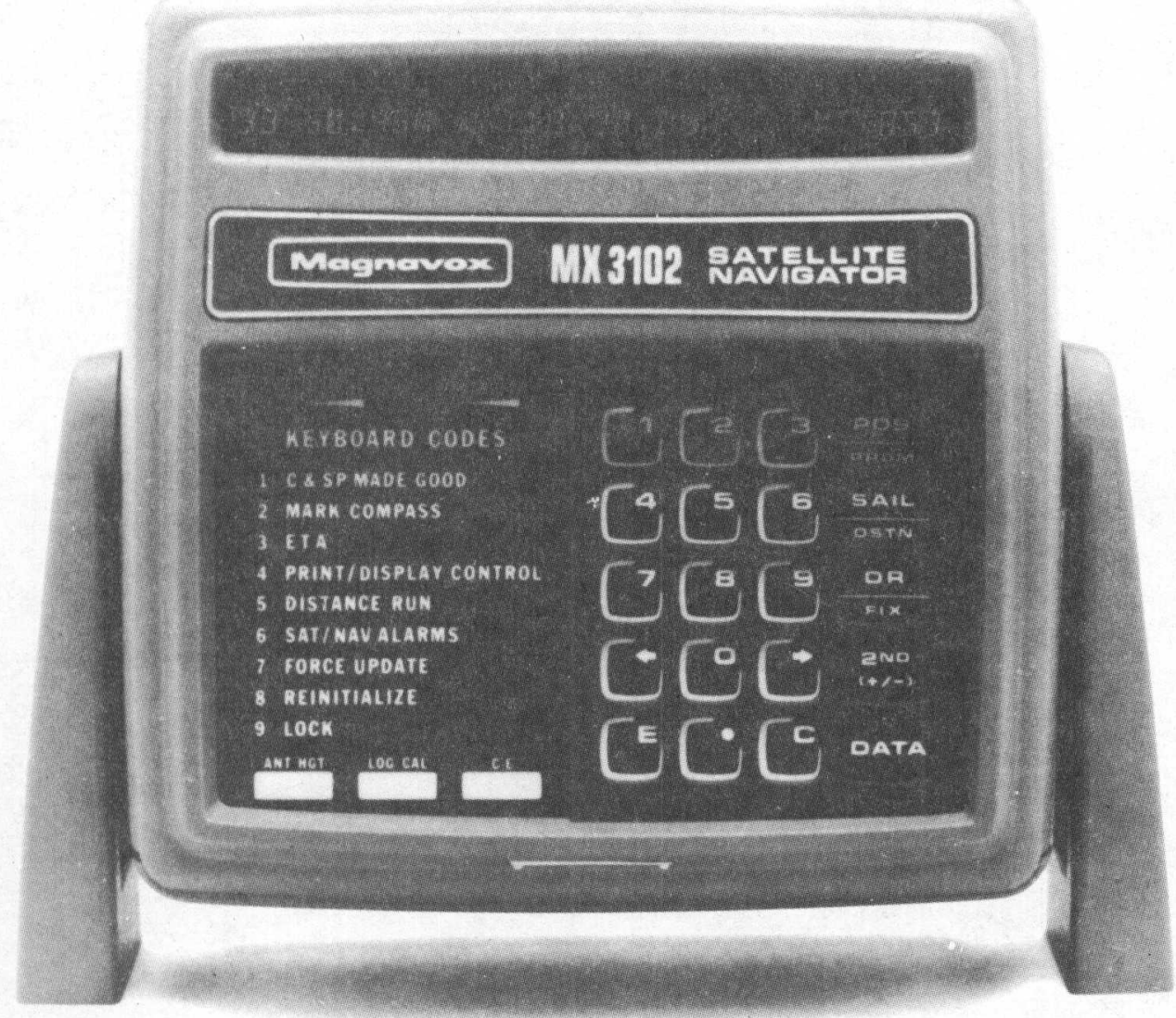

Just a few years ago, a satnav with you the exact information you need to all the capabilities of the MX 3102 would have cost twice as much! This welcome combination of advanced features and modest price is the direct result of state-of-the-art integrated electronics. And easy use is also part of the package.

Up-to-the-Second Facts.

Calculations of position, course speed, and set and drift are made continuously and automatically. The built-in speed and heading interface connects to your choice of speed $\log$ and gyro or optional magnetic compasses for automatic speed and heading inputs.

The straightforward keyboard and large display concentrate on giving know. You're never subjected to a confusing collection of unnecessary details.

The Basics. And Beyond.

An antenna/preamplifier is standard. So is programmed tracking

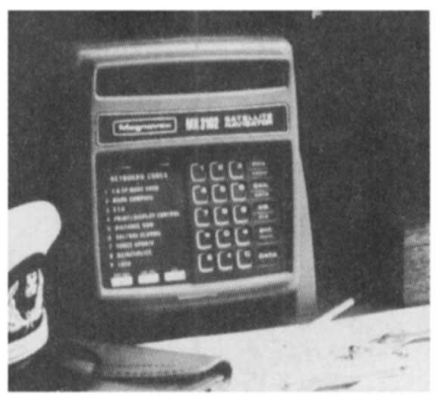

(iii) that provides $10 \%$ more usable fixes than most competitive equipment. There's also an optional printer for permanent records of your location, and a CRT for additional display of information.

Find out how you can get Magnavox performance at an unex. pectedly low price. For details, contact: Marine Systems Division, Magnavox Advanced Products and Systems Co., 2829 Maricopa St. Torrance, Calif. 90503 U.S.A. Tèlephone (213) 618-1200. Telex 696101. Cable MAGNAMAR. Sales and service worldwide.

Magnavox Number One In Satnav 


\section{'NAVIGATION' No. 116}

The October 1981 issue of Navigation (Paris), the quarterly Journal of the French Institute of Navigation, contains the following papers.

AVIS IMPORTANT

I. Chronique du navigant

1 Le routing dans la Manche, par A. N. CockCRofT

2 Capacité résiduelle de manœuvre de pétroliers privés de propulsion ou de moyens de gouverne, par B. NIZERY, I.R.C.N.

3 Les grandes zones de manœuvre terminale, par J. L. Garnier, D.N.A.

4 Parade exemplaire d'un puissant cyclone, par J. DARCHEN

5 Vingt ans après, par J. P. BoILLOT

II. ÉtUDES, MÉTHODES ET ARTIFICES DE NAVIGATION

Le procédé de demain: Le segment capable sphérique

III. L'HistoIre ET LA NAVIGATION

L'art pervers de la navigation, par J. P. NeRAudau

IV. INFORMATIONS

V. Chronique DeS livres et ReVue

\section{'NAVIGATION (USA)'}

Volume 28, No. 1 (Spring 1981) of Navigation, the quarterly Journal of the American Institute of Navigation, contains the following papers.

Most Probable Fix Position Reduction

G. D. Morrison

Safer Navigation at Minimum Cost

D. G. Hindle

A Handheld Collision Avoidance Aid $J$. D. Luse

Aids to Navigation Positioning Project

James E. Smith, Jr.

The Role of the Earth's Shape in Navigation; An Example

$W$. Kuebler and $S$. Sommers

Navigation Systems for Dynamic Positioning Vessels

Thor K. Skoland and Victor Prushan

An Analytical Solution of the Two Star Sight Problem of Celestial Navigation

James A. Van Allen

K-12 Method by Calculator: A Single Program for All Celestial Fixes,

Directly or by Position Lines

S. Kotlaric

Unambiguous Two Body Fix Methods Derived from Crystallographic

Principles

Torben Kjer

Vertical Sextant Angles Short of the Horizon

W. C. Marlow

Reviews of Recent Books

The Institute's Professional Forum

T. D. Davies, Norman G. Cubberly

The Institute's Professional File 


\section{Aworld of marine electronics.}

Whether you go down to the sea in bigor small ships; in near or distant waters, you know you can depend on Racal-Decca.

Because Racal-Decca provides an unmatched range of products and services with a reputation for the highest standards of performance, quality and reliability. Products and services for the professional mariner, for the offshore oil and gas industry, and for a wide variety of other maritime users and organizations. A range which includes.

\section{Autopilots and steering controls}

- Engine-room control and surveillance systems

- Hydrographic and oceanographic surveys

- Integrated marine navigation systems

- Radars for every type of civil and naval application

- Radio position-fixing systems.

And you know that, if you need help, Racal- Decca will look after you - wherever you are. With a network of 530 depots and service centres around the globe, RacalDecca is truly a world of marine electronics.

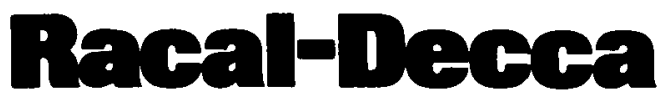

Racal-Decca Limited New Malden, Surrey KT34NW, England. Tel: 01-9422488 Telex: 22891

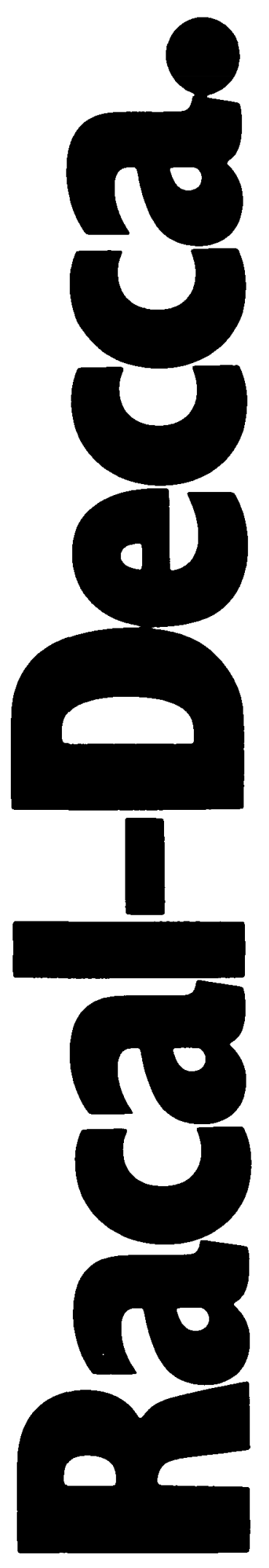




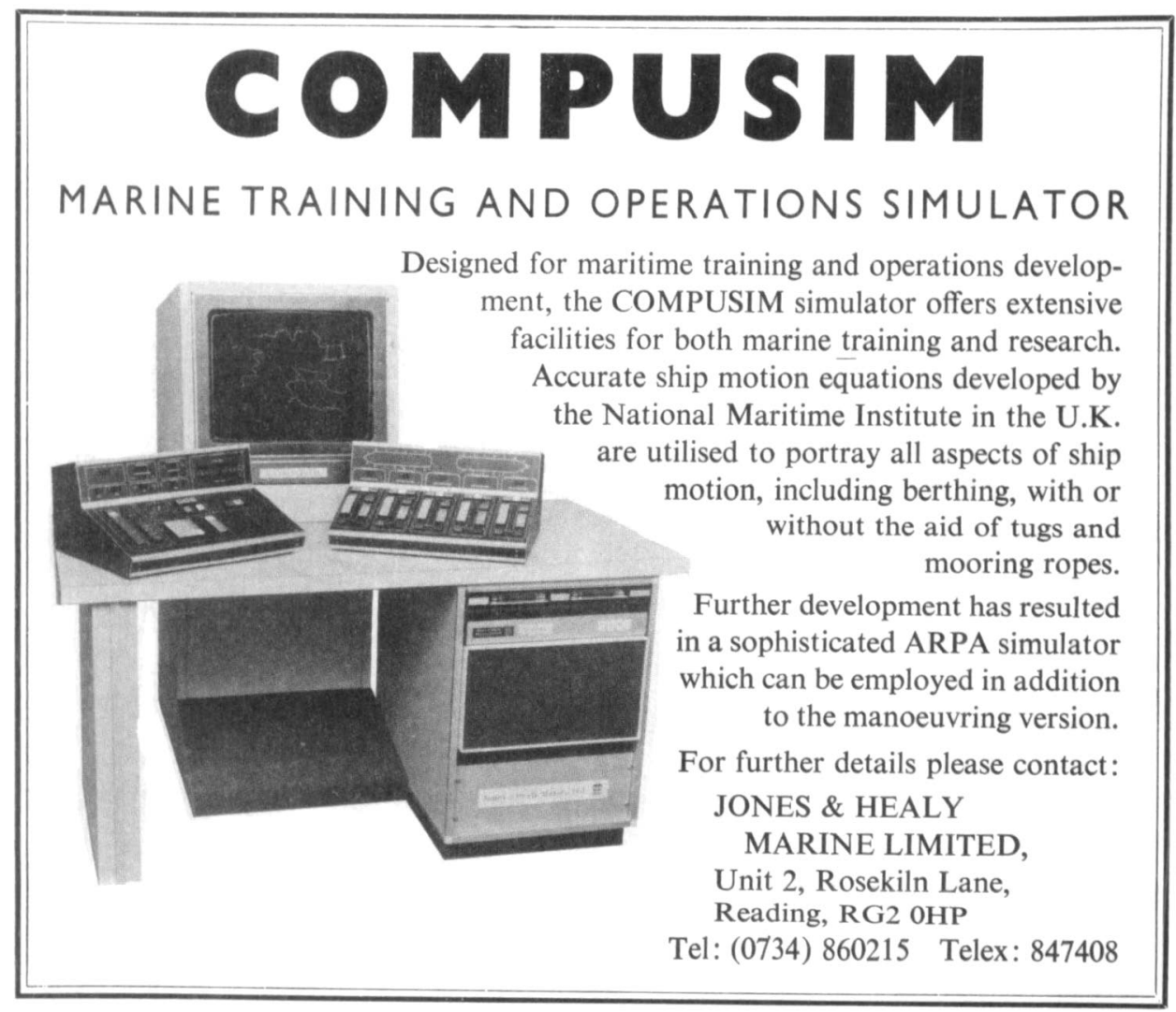




\section{THE ROYAL INSTITUTE OF NAVIGATION}

7 HE OBJECT of the Institute is to unite in one body those who are concerned with or who are interested in the science and art of navigation. Membership is not restricted to those who hold professional qualifications, but is open to others who wish to further the aims of the Institute.

By coordinating the knowledge and achievements of marine and air navigators, scientists and those associated with the development and production of navigational equipment, the work of the Institute is directed towards raising the standard of navigation. In the field of education it is the aim of the Institute to bring practical navigators into contact with teachers and research workers to increase a common appreciation of the issues involved. It is an object of the Institute to encourage research in equipment and methods; through its publications it gives a wide circulation to original work on navigation so that new developments and suggestions can be appreciated by those most directly concerned with them.

The activities of the Institute include the holding of monthly meetings to discuss specific problems, the publication of a Journal and of other works concerned with different aspects of navigation, and such other activities as the Council may deen necessary to promote knowledge in navigation and its associated sciences.

The Journal of Novigation is issued free to all Members and contains a full account of the Institute's proceedings. It prints the papers which are presented at meetings, together with their ensuing discussion, and other original papers contributing to the science of navigation. It also contains a record of current navigational work, reviews of important books, and general papers of interest to navigators and those with similar interests.

The work of the Institute is coordinated with that of similar societies abroad, whose proceedings are available to members.

Membership. There are five classes of membership of the Institute:

(1) HONORARY MEMBERS, who shall be distinguished persons upon whom the Council may see fit to confer an honorary distinction.

(2) FELLows, who shall be members, of at least three years' standing who, in the opinion of the Council, have made a contribution of value to navigation.

(3) MEMBERS, who shall be persons over twenty-one years of age who can satisfy the Council of their interest in navigation.

(4) STUDENT MEMBERs, who shall be persons under twenty-five years of age studying with a view to making navigation, or an allied interest, their career.

(5) CORPORATE MEMBERs, who shall be companies, universities, navigation schools, government departments and other organizations, here and abroad, who are directly or indirectly interested in the science of navigation. Corporate Members are entitled to send representative to all Institute meetings and to receive six copies of the Journal, and other publications. They are encouraged to take an active part in the Institute's work. Applications should be sent by letter addressed to the Director.

Subscriptions. Annual subscriptions to the Institute are payable in advance as follows:

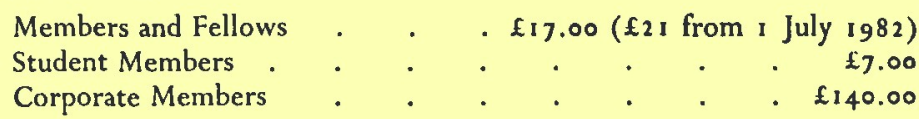

The Institute's financial year begins on I July. Members in any category who are elected after I January in any year are only due for one half of their subscription until I July, when the full subscription for the next year becomes due. 
CAMBRIDGE UNIVERSITY PRESS

The Pitt Building, Trumpington Street, Cambridge CB2 וRP 32 East 57 th Street, New York, N.Y. 10022

Printed in Great Britain at the University Press, Combridge 